\title{
Nucleus of the Strategic Planning of an Integrated University Information System
}

\author{
Ljerka Luić \\ B4B d.o.o. \\ Ulica grada Vukovara 271, Zagreb, Croatia \\ ljerka.luic@b4b.hr \\ Ana Fudurić \\ Karlovac University of Applied Sciences \\ Trg J. J. Strossmayera 9, Karlovac, Croatia \\ ana.fuduric@yahoo.com
}

\section{Summary}

Nucleus of the strategic planning of the integrated information system (SP-IIS) is determined by implication of mutual impacts of its four principal elements: information strategy, info management strategy, info technology strategy and change management strategy, based on which the subject of research is described in the paper, viewed from the aspect of social dimension alignment of the academic (elected) and administrative (permanent) university management with the aim of drafting a simulation model of strategic planning of the integrated university information system (SP-IIS-Uni). An analysis of the research results provided evidence indicating that, with respect to the strategic planning of an integrated business information system (SP-IBIS-Uni), university top management expresses the greatest interest in the planning of alignment between the business information system (BIS) and the academic information system (AIS). They believe the impact of using ICT is crucial for their future work and operation of the university, but also necessary for more efficient integration with university institutions in EU countries. In the context of investigating this domain, the nucleus of the strategic planning of an integrated university information system is viewed as an implication of mutual impacts of information strategy, info management strategy, info technology strategy and change management strategy, but also the social implications by which the SPIIS-Uni nucleus strategy affects the information \& organizational environment of the university. Elaborated premises, hypotheses set and a comparative analysis of results from similar research resulted in a conclusion on an inseparable synergic impact of nucleus particles on the strategic planning of integrated university information system development.

Keywords: nucleus, strategic planning, information system, university 


\section{Introduction}

In the concept, strategic planning is deceptively simple. The analysis includes the present and expected future states and determines the direction and development of resources required to accomplish the mission. In reality, strategic planning is an extremely complex process requiring a systematic approach to determining and analyzing factors within and beyond the business system. A business system's information system is of great importance for its viability and operation, which is why its strategic planning is as important as the strategic planning of the business system. Based on this premise, the development of modern integrated information systems is a foreseeably demanding and comprehensive organizational and financial venture for any business system, including an academic one, which needs to be strategically planned in accordance with the strategic business plan.

\section{Background}

From the scientific research viewpoint, investigating strategic planning of information systems (SPIS) is not easy, especially considering the fact that this discipline of information science is very young. In initial research of information systems where works of Burrell and Morgan ${ }^{1}$, Wood-Harper ${ }^{2}$, Klein and Lyytinen $^{3}$ and Iivari ${ }^{4}$ dominate, the researchers agreed upon the identification of four basic paradigms defined as functionalism, interpretation, radical humanism and radical structuralism. These paradigms may be analyzed by investigating four basic dimensions: ontology, human nature, epistemology and methodology. It is unquestionable that the two dominant paradigms in the studying of this area are the interpretative and functional paradigms. Among others, Han and Jones ${ }^{5}$ additionally broaden the view and draw attention to the fact that a new research body is being developed that assumes a more pragmatic position because, according to Orlikowski ${ }^{6}$, early work considered technology to be an objective external force that would have relatively deterministic effects on organizational characteristics such as structure. Conversely, a group of researchers later focused on human activity with respect to technology, perceiving it more as a product of joint interpretations or interventions.

\footnotetext{
${ }^{1}$ Burrell, G., Morgan, G., Sociological Paradigms and Organisational Analysis: Elements of the Sociology of Corporate Life, Ashgate Publishers, 1979

${ }^{2}$ Wood-Harper, T., Research Methods in Information Systems, Elsever Science Publishers, 1985

${ }^{3}$ Klein, H.K., Lyytinen, K., The Poverty of Scientism in Information Systems, Manchester, 1984

${ }^{4}$ Iivari, J., A paradigmatic analysis of contemporary schools of IS development, European Journal of Information Systems, 1(4), 1991, pp. 249-272

${ }^{5}$ Han, P., Jones, M., The dialectics of Information Systems. University of Cambridge Research Paper: Judge Institute of Management Studies, 1993

${ }^{6}$ Orlikowski, W. J, The duality of technology: rethinking the concept of technology in organisations, Organisation Science, 3(3), 1992, pp. 398-427
} 
The third group reverted to technology, however, as "soft" determinism where technology is defined as an external force having its effects which are modeled by the human factor and organizational contexts. The research described in this paper integrated the abovementioned concepts through paradigmatic frameworks and is in this context classified in the third group, based on the theory of structuralism and focused on investigating the social dimension of alignment. Except for several statements concerning the domain of the social dimension of alignment, defined by Reich i Benbasat ${ }^{\dagger}$ as the state in which business and IT executives within an organization understand and are committed to business and IT objectives, mission and plans, and several papers published by Nelson and Cooprider $^{8}$, Taylor-Cummings ${ }^{9}$, Subramani, Henderson and Cooprider ${ }^{10}$, and Reich and Benbasat ${ }^{11}$, there are no systematic scientific papers investigating methods of the social dimension of alignment viewed through the time dimension and focused on measuring the state in which different groups of executives within a line of business understand and take part in the strategic planning of an integrated information system contemplated in the research, the results of which are provided below.

\section{Problem Statement}

Academic circles show a high level of disagreement on how to position the making of a decision to initiate the strategic planning of information systems, who should be responsible and which persons from which domains should be actively involved. This disagreement is often associated with positioning information in the center of the success of university organizations. The way in which information is used (automatically or manually integrated) is a key factor that determines how much each department and university as whole is efficient and competitive. It is unquestionable that, as regards the relevance, possibility of dissemination and support to integral academic functions, information is the principal element of primary university activities such as teaching and research activities. It is also important to note that a university is often expected to generate information relevant to specific stakeholders, from the founder to the greater social community. Providing all this information is very often a difficult and major challenge to a university and the academic community as a whole.

\footnotetext{
${ }^{7}$ Reich, B.H., Benbasat, I., Measuring the linkage between business and information technology objectives, MIS Quarterly, 20(1), 1996, pp. 55-81

${ }^{8}$ Nelson, K.M., Cooprider, J.G., The contribution of shared knowledge to IT Group performance, MIS Quarterly, 20(4), 1996, pp. 409-432

${ }^{9}$ Taylor-Cummings, A., Bridging the user-IS Gap, A study of major information systems projects, Journal of Information Technology, (13), 1998, pp. 29-54

${ }^{10}$ Subramani, M., Henderson, J.C., Cooprider, J., Linking IS-user partnerships to IS performance: a socio-cognitive perspective. MISRC Working Paper Series WP 99-01. Boston, 1999

${ }^{11}$ Reich, B.H., Benbasat, I., Measuring the Information Systems - Business Strategy Relationship. In: Galliers, R.D., Leidner, D.E., Strategic Information Management: Challenges and Strategies in Managing Information Systems. Oxford: Elsevier Butterworth-Heinemann, 2003, pp. 265-310
} 
After the Bologna process was implemented in the higher education system of the Republic of Croatia, an acute problem arose in the optimization of using available resources: budget funds, internal revenue, staff, space and equipment, in particular the optimization of allocating funds by introducing lump sum funding. It is therefore necessary for the development and management of a complex system such as an integrated information system to design a uniform information strategy as a link between the academic strategy, the information system strategy and the business strategy. The complexity of this process requires specific forms of strategic thinking, planning and activity management, and ultimately strategic planning of the university.

\section{Nucleus of the Strategic Planning of an Integrated Information System}

According to Ward and Peppard, the nucleus of the strategic planning of an integrated information system is determined by the implications of the mutual impacts between its particles: Information Strategy, Info Management Strategy, Info Technology Strategy, and Change Management Strategy, based on which the subject of research described in this paper is observed from the viewpoint of the social dimension of the short-term and long-term alignment of academic (elected) and administrative (permanent) management of the university and its constituents.

Figure 1: Particles of the Information System Strategic Planning Nucleus

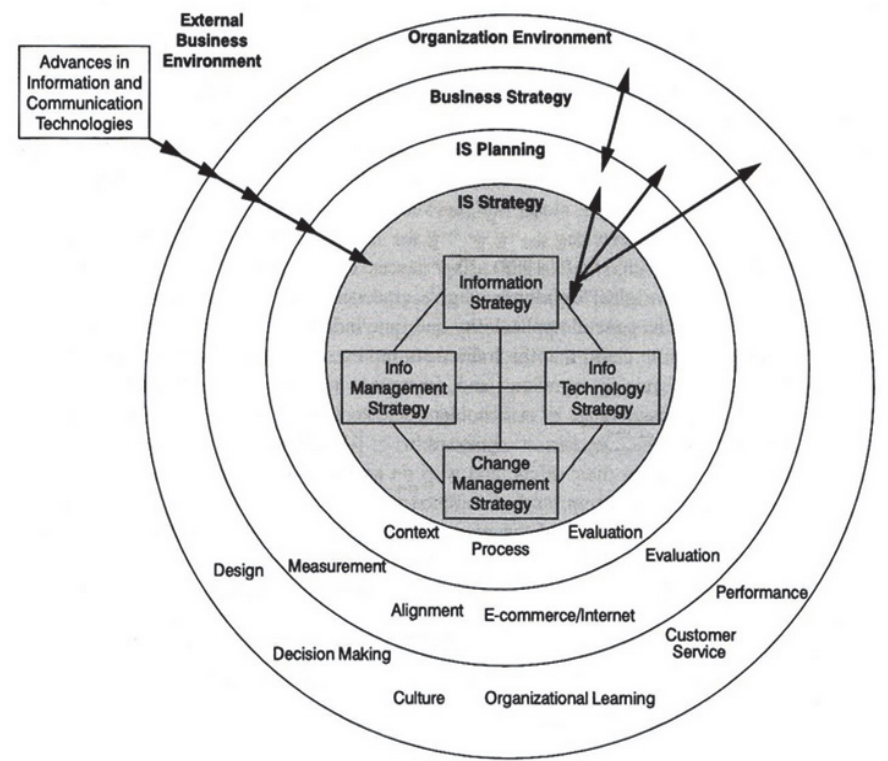

Source: Ward J., Peppard J. Strategic planning for Information systems, Wiley series in information systems, 2010, p. 137 
Strategic planning of information systems remains the most important issue in many organizations. SPIS cannot be understood by taking into consideration only formal methods. Planning processes and plan implementation are just as important, so Galliers and Leidner accordingly propose five different approaches to SPIS: business-led, method-driven, administrative, technological and organizational approaches. ${ }^{12}$ Each approach has different characteristics and, consequently, different chances to be successful. The results of completed research show that the organizational approach is the most efficient one. The taxonomy of these five approaches also offers a diagnostic tool for analyzing and evaluating an organization's experience with SPIS. It is recommended for SPIS to focus on the following areas: ${ }^{13}$

- investing in IT strategy according to business objectives

- using IT to gain competitive advantage

- directing efficient management of information strategy resources

- developing technological policies and architectures.

The above graphically and textually elaborated statements show that the strategy nucleus particles form a synergic, almost indivisible unit, which points to the conclusion that their interactive relations are highly relevant to the strategic planning of integrated information systems (SP-IIS).

\section{Material and Methodology \\ Research Sample}

The research on which this paper is based was conducted on all 7 universities in the Republic of Croatia represented by their Rectorates, and their 66 constituents (faculties) represented by their Dean's Offices. The final selection of 73 higher-education institutions of a university nature was ultimately viewed as a reflection of Yin's ${ }^{15}$ strategy of "literal replication" where all cases are theoretically the same, which achieves the principal objective of the research as it was conducted on $68.5 \%$ of all institutions and this allowed for statistically significant results to be provided, as defined by Reich and Benbasat ${ }^{16}$. The final sample based on said stratification was organized according to Sumsion's ${ }^{17}$ typol-

\footnotetext{
${ }^{12}$ Galliers R.D. Leidner D.E., Strategic Information Management: Challenges and Strategies in Managing Information Systems. Oxford: Elsevier Butterworth-Heinemann, 2003, p. 81

${ }^{13}$ Ibid

${ }^{14}$ Fudurić, A, The nucleus of the business and information strategy, Graduate thesis, Karlovac University of Applied Sciences, 2014, p. 35

${ }^{15}$ Yin, R. K., Case Study Research: Design and Methods, London: Sage Publications, 2003

${ }^{16}$ Reich, B.H., Benbasat, I., Measuring the Information Systems - Business Strategy Relationship. In: Galliers, R.D., Leidner, D.E., Strategic Information Management: Challenges and Strategies in Managing Information Systems. Oxford: Elsevier Butterworth-Heinemann, 2000

${ }^{17}$ Sumsion, J., Survey of resources and uses in Higher Education Libraries. Loughborough, Library and Information Statistics Unit, Loughborough University of Technology, 1994
} 
ogy and observed dually: (1) from the viewpoint of legal entities, 73 public institutions of a university nature, and (2) 365 individuals (executives).

\section{Research Methodology}

Based on the fact that a survey questionnaire is a fundamental measuring instrument for data gathering in social sciences, including information science, this measuring instrument was used for the purposes of the research concerned. A total of 24 questions were grouped in three thematic units: (1) Alignment of the Business and Academic Information Systems, (2) Planning of Integrated Information System Development, and (3) Using ICT. The subjects completed the questionnaire personally, all subjects within an institution at the same time in the presence of a researcher, a co-author of this paper.

\section{Hypotheses}

An analysis of earlier similar research indicated that there are no generally accepted models for investigating the social dimension of alignment. It was therefore proceeded with identifying the categories of factors that may affect alignment according to theoretical and empirical literature.

By using relations studied in literature and defining new ones, these factors were organized in a research model containing four constructs distributed across two levels. These constructs were identified as KNOWLEDGE, PLANNING, ATTITUDE AND FUNDING and allocated by taking into account the time dimension to short-term and long-term alignment levels. The main hypothesis and sub-hypotheses were set based on these statements, defining each construct of the model as provided below in a logical order.

$\mathrm{H}_{1}$ : The strategic planning of an integrated information system (SP-IIS) largely depends on the long-term alignment of a university institution's management, on which the KNOWLEDGE and FUNDING constructs have a direct impact. $\mathrm{HO}_{2}$ : The common KNOWLEDGE of the domain (SP-IIS) has the greatest weighting factor and is the only one distinguishing between management on the short-term and long-term alignment levels.

$\mathrm{HO}_{3}$ : The perception of the importance of the strategic PLANNING of an integrated information system largely depends on the type of executive function (permanent vs. elected).

$\mathrm{HO}_{4}$ : The ATTITUDE of management directly affects the level of their perception regarding the significance of the strategic planning of an integrated information system. $\mathrm{H}_{5}$ : The mechanism and sources of university's FUNDING have a direct impact on the strategic PLANNING of an integrated information system. 
$\mathrm{H}_{6}$ : The long-term alignment of management with SP-IIS is defined on a causal basis: KNOWLEDGE $\rightarrow$ ATTITUDE $\rightarrow$ FUNDING $\rightarrow$ PLANNING. ${ }^{18}$

\section{Results}

The main hypothesis was fully confirmed. Namely, the results of the linear regression model with PLANNING as a dependent variable and ATTITUDE, FUNDING and PLANNING as independent variables show that the independent variables explain a statistically significant part of the variability of the dependent variable PLANNING, while a PATH analysis ${ }^{19}$ demonstrated that KNOWLEDGE and FUNDING reflect the state where permanent and elected executives share a common vision with respect to the strategic planning of an integrated business information system. ${ }^{20}$

\section{Discussion}

\section{The Main Scientific Evidence Obtained by the Research}

The main evidence indicates the fact that, as regards the strategic planning of an integrated business information system, university management shows the greatest interest in the domain concerning the alignment of the business and academic information systems, followed by the use of ICT, while their interest is the least focused on the planning of integrated information system development. Although not the largest, a sufficiently substantial share of management believes the success of their institution's current operation is not dependent upon the impact of using ICT, but that it is crucial for their future work and operation. The second main evidence confirms that elected management places much more importance on a systematic approach to the building of IS-Uni which includes project planning and is primarily based on organizing the existing processes and information flows, compared to permanent management that hardly notices these activities.

By observing this evidence resulting from a descriptive analysis on an integral basis, it is possible to establish that strategic thinking of the use of information sources is substantially more present in large universities compared to small universities, which implies the assumption that a large university's management is more inclined to the strategic planning of integrated business information systems. In addition, the above explanations indicate four key impacts: knowledge, planning, attitude and funding, which were tentatively assumed to affect the level of management's perception of the domain concerning the stra-

${ }^{18}$ Luić, Lj., Strategic Planning of Integrated Business-Information Systems - Model Design Example of Higher Education, Doctoral thesis, Faculty of Humanities and Social Sciences of the University of Zagreb, Croatia, 2009, p. 31

${ }^{19}$ Lleras, C., Path analysis, Encyclopedia of Social Measurement, Vol. 3, No. 1, 2005, pp. 25-30

${ }^{20}$ Luić, Lj., Strategic Planning of Integrated Business-Information Systems - Model Design Example of Higher Education, Doctoral thesis, Faculty of Faculty of Humanities and Social Sciences of the University of Zagreb, Croatia, 2009, pp. 166-169 
tegic planning of an integrated business information system, as demonstrated by using scientific methods. ${ }^{21}$

\section{A Comparison with Evidence Obtained in Similar Research}

Ljerka Luić vs. Allen David (1995) Information Systems Strategy Formation in Higher Education Institutions. Information Research, 1(1) Both research papers confirmed the existence of a certain degree of subject's awareness of the need for strategic planning of information resources and making them the center of interest for the institutions represented by them. Compared to Allen's research, the qualitative contribution of the research evidence obtained by the co-author of this paper is reflected in the quantitative assessment of the degree of awareness of the need for strategic planning of integrated information systems, which in relation to the determining whether or not it exists reflects a certain contribution to the development of said research.

Ljerka Luić vs. Francis Greene, Brendan Loughridge i Tom Wilson (1996) The Management Information Needs of Academic Heads of Departments in Universities: a Critical Success Factors Approach. British Library Research and Development Department. A research paper by Greene, Loughridge and Wilson contemplating the information needs of department heads provided evidence that the balance between the internal and external critical success factors for a university depends on four key factors: the political \& economic environment, the institutional environment, the relative position of the department, and the culture of the department. If the strategic planning of an integrated business information system is perceived as part of university management's needs for management information, the evidence obtained within the research conducted by the co-author of this paper may be compared with the abovementioned evidence in the context of achieving a balance between different management groups, which in relation to the comparable research also depends on four key influential factors which are, however, very different. In this research paper, they are: knowledge, funding, attitude and planning.

Ljerka Luić vs. Marcella Rita i Knox Karl (2004) Systems for the management of information in a university context: an investigation of user need. Information Research. Marcella and Knox investigated the efficiency of the existing data and information systems supporting the work of management and academic, research and administrative staff of higher education institutions. The evidence obtained by them indicate the fact that actual flaws exist in the implementation of the analyzed university's information strategy and that such flaws need to be dealt with as part of the development which needs to focus on improving the future strategic efficiency. The solutions proposed for improving the existing information systems indicate the fact that senior executives are aware that the main priority in the implementation of such improvements is the

${ }^{21}$ Ibid, pp. 136-138 
development of a single integrated system that is flexible enough to meet specific demands while ensuring maximum accuracy and reliability of system data which needs to be quick, user-friendly and designed to support the actual operating functions, in particular those of administrative staff.

Similar evidence was obtained by the co-author of this paper. Namely, her results indicate the fact that actual flaws exist in the university management's strategic thinking regarding the development and implementation of an integrated business information system. Both research papers show a clear attitude of management with respect to the development of a single integrated system flexible enough to meet specific demands. The fact that the research studies were conducted independently, with a delay and in different cultural and business environments additionally confirms the need to contemplate and use SPIPIS-Uni. ${ }^{22}$

\section{Recommendations for Further Research}

An extension of the Strategic Planning of an Integrated Information System is justified in the context of contributing scientific evidence such as discovering new algorithms and variables that may be used to describe more precisely the changes occurring within each construct of the model and their interactions, but also in the context of its actual use as the efficiency of using new technologies in the operation of a university lies in the synergic use of strategic planning nucleus particles in university management's strategic thinking.

\section{Conclusion}

As a result of the implication of the mutual impacts between its main particles (Information Strategy, Info Management Strategy, Info Technology Strategy and Change Management Strategy), the IS strategic planning nucleus affects the overall information environment of a university: academic, business and organizational. In this process, nucleus particles are almost inseparable from each other and their mutual link is of great importance for the strategic planning of information systems and their entire lifecycles. ${ }^{23}$

An analysis of the research results provided evidence indicating the fact that, as regards the strategic planning of an integrated university information system, management of a higher education institution expresses the greatest interest in the domain concerning the alignment of the business and academic information systems. In addition, the results obtained indicate the fact that the opinions of elected executives are much more represented in decisions concerning the informatization domain compared to permanent executives, however, neither group recognizes IT professionals as adequate collocutors on the subject of an

\footnotetext{
${ }^{22}$ Ibid, pp. 170-172

${ }^{23}$ Fudurić, A, The nucleus of the business and information strategy, Graduate thesis, Karlovac University of Applied Sciences, 2014, p. 64
} 
integrated business information system, which foreseeably also excludes the participants in the process of the strategic planning thereof. ${ }^{24}$

\section{Acknowledgments}

The publication of this paper was supported by the B4B, to which the authors of this article are grateful for its substantial support.

\section{References}

Burrell, Gibson; Morgan, Gareth. Sociological Paradigms and Organisational Analysis: Elements of the Sociology of Corporate Life. Farnham: Ashgate Publishing, 2007

Fudurić, Ana. The nucleus of the business and information strategy, Graduate thesis, Karlovac: Karlovac University of Applied Sciences, 2014

Galliers, Robert; Leidner, Dorothy. Strategic Information Management: Challenges and Strategies in Managing Information Systems. Oxford: Elsevier Butterworth-Heinemann, 2003,

Han, P., Jones, Matthew. The dialectics of Information Systems. Research Paper. Cambridge: University of Cambridge, Judge Institute of Management Studies, 1993

Iivari, Juhani. A paradigmatic analysis of contemporary schools of IS development // European Journal of Information Systems, volume 1 (1991), number 4; pp. 249-272

Klein, Heinz; Lyytinen, Kalle. The Poverty of Scientism in Information Systems, In Allen, David. Information systems strategy formation in Higher Education Institutions// Information Research, 1(1) Available at: http://InformationR.net/ir/1-1/paper3.html (7 September 2015)

Lleras, Christy. Path analysis // Encyclopedia of Social Measurement, volume 3 (2005), number 1, pp. 25-30

Luić, Ljerka. Strategic Planning of Integrated Business-Information Systems - Model Design Example of Higher Education, Doctoral thesis. Zagreb: Faculty of Humanities and Social Sciences of the University of Zagreb, 2009

Nelson, Kay, Cooprider, Jay. The contribution of shared knowledge to IT Group performance // MIS Quarterly, volume 20 (1996) number 4, pp. 409-432

Orlikowski, Wanda. The duality of technology: rethinking the concept of technology in organisations // Organisation Science, volume 3 (1992), number 3, pp. 398-427

Reich, Blaize Horner, Benbasat, Izak. Measuring the Information Systems - Business Strategy Relationship. In: Galliers, Robert; Leidner, Dorothy (eds.) Strategic Information Management: Challenges and Strategies in Managing Information Systems. Oxford: Elsevier Butterworth-Heinemann, 2003, pp. 265-310

Reich, Blaize Horner; Benbasat, Izak. Measuring the linkage between business and information technology objectives // MIS Quarterly, volume 20 (1996) number 1, pp. 55-81

Subramani, Mani; Henderson, John; Cooprider, Jay. Linking IS-user partnerships to IS performance: a socio-cognitive perspective, MISRC Working Paper Series WP 99-01. Boston: Systems Research Center at Boston University, 1999

Sumsion, John. Survey of resources and uses in Higher Education Libraries. Loughborough, Library and Information Statistics Unit, Loughborough University of Technology, 1994

Taylor-Cummings, Andrea. Bridging the user-IS Gap, A study of major information systems projects // Journal of Information Technology, volume 13 (1998), pp. 29-54

Wood-Harper, Trevor. Research methods in information systems: using action research. In Mumford, E., Hirschheim, R., Fitzgerald, G. and Wood-Harper, T. (eds.) Research Methods in Information Systems. Amsterdam: Elsever Science Publishers B.V North Holland, 1985

Yin, Robert. Case Study Research: Design and Methods, London: SAGE Publications, 2003

${ }^{24}$ Luić, Lj., Strategic Planning of Integrated Business-Information Systems - Model Design Example of Higher Education, Doctoral thesis, Faculty of Faculty of Humanities and Social Sciences of the University of Zagreb, 2009, p. 176 